\title{
Comparison of Direct Medical Care Costs Between Erosive Reflux Disease and Non-erosive Reflux Disease in Korean Tertiary Medical Center
}

\author{
Pyoung Ju Seo, MD ${ }^{1}$, Nayoung Kim, MD ${ }^{1 *}$, Jane $C$ Oh, MD ${ }^{2}$, Byoung Hwan Lee, MD ${ }^{1}$, Cheol Min Shin, MD ${ }^{1}$, \\ Seungchul Suh, MD ${ }^{1}$, Hyunkyung Park, MD ${ }^{1}$, Ryoung Hee Nam, MSc ${ }^{1}$, Jin A Cha, CRC ${ }^{1}$, Young Soo Park, MD ${ }^{1}$ and \\ Dong Ho Lee, MD ${ }^{1}$
}

${ }^{1}$ Department of Internal Medicine, Seoul National University Bundang Hospital, Seongnam, Gyeonggi-do, Korea, ${ }^{2}$ Yonsei Plus Clinic, Seongnam, Gyeonggi-do, Korea

\begin{abstract}
Background/Aims
Gastroesophageal reflux disease is one of the most common and frequent chronic disease requiring considerable cost. We investigated the medical care costs in the erosive reflux disease (ERD) and non-erosive reflux disease (NERD).
\end{abstract}

\section{Methods}

The risk factors and the direct medical care costs were analyzed retrospectively in the ERD (178 patients) and NERD (183 patients) groups for a follow up period of 2 years.

\section{Results}

Logistic regression analysis showed that the ERD was more frequent in the groups of male gender, alcohol consumption, higher body mass index $\left(\geq 25 \mathrm{~kg} / \mathrm{m}^{2}\right.$ ), hiatal hernia, and higher triglyceride levels ( $\geq 150 \mathrm{mg} / \mathrm{dL}$ ). The direct medical care costs per person for 2 years were found to be $\$ 384.8$ (ERD) and $\$ 412.9$ (NERD) without statistically significant differences ( $p=$ 0.364). However, $9.3 \%(17 / 183)$ of the NERD patients had visited the emergency room compared to $3.4 \%(6 / 178)$ of the ERD patients $(p=0.029)$. In addition, more NERD patients were hospitalized than ERD patients $(p=0.006)$, and because of the longer hospitalization period, the medical costs in NERD patients were higher than ERD patients $(p=0.038)$.

\section{Conclusions}

In spite of the different risk factors for ERD and NERD, total direct medical care costs were similar between the ERD and NERD group. However, more visits to emergency room and longer hospitalization period with more hospitalization costs in NERD patients account for the differences in medical service and usage distribution between the 2 groups.

(J Neurogastroenterol Motil 2010;16:265-273)

\section{Key Words}

Gastroesophageal reflux, Health care costs, Risk factors

Received: June 28, 2010 Revised: July 11, 2010 Accepted: July 12, 2010

(c) This is an Open Access article distributed under the terms of the Creative Commons Attribution Non-Commercial License (http://creativecommons. org/licenses/by-nc/3.0) which permits unrestricted non-commercial use, distribution, and reproduction in any medium, provided the original work is properly cited.

*Correspondence: Nayoung Kim, MD

Department of Internal Medicine, Seoul National University Bundang Hospital, 300 Gumi-dong, Bundang-gu, Seongnam, Gyeonggi-do 463-707, Korea

Tel: +82-31-787-7008, Fax: +82-31-787-4051, E-mail: nayoungkim49@empal.com

Financial support: This study was supported by grant from the Liver Research Foundation fund in 2009.

Conflicts of interest: None. 


\section{Introduction}

Gastroesophageal reflux disease (GERD) is a common and well-known digestive disorder and it often leads to troublesome symptoms and/or complication such as heartburn and acid regurgitation caused by the reflux of stomach contents. ${ }^{1}$ Based on the findings of esophago-gastro-duodenoscopy (EGD), patients with GERD can be subdivided into 2 categories: those with or without erosive reflux disease (ERD). Patients with ERD have identifiable mucosal breaks in the distal esophagus on EGD whereas the non-erosive reflux disease (NERD) patients show normal-appearance of mucosa. Although the prevalence of GERD is different by the country or survey method, it is well known that $10 \%-20 \%$ of the Western population and $5 \%$ of the Asian experiences heartburn and/or acid regurgitation at least once a week. ${ }^{2}$ The prevalence of GERD in Korea used to be similar or slightly lower than other Asian countries until recently, however it is increasing with rises in overweight and a shift from the Korean traditional diet to a westernized one.

In the past studies, NERD was considered as one of the light symptoms of GERD which would progress to ERD gradually, and it was expected to eventually develop to ERD. ${ }^{3,4}$ However, recent studies showed treating NERD to be more difficult than ERD and the rarity in developing ERD from NERD, suggesting ERD and NERD as different phenotypes with their own pathophysiological relevances and clinical characteristics. ${ }^{5,6}$ Moreover, Fass et $\mathrm{al}^{7}$ reported that NERD patient was more likely to have heartburns induced by intraesophageal stimuli which were increased by psychological stresses and emotional perturbations. Therefore, we hypothesized that there would be a difference in the medical care costs between ERD and NERD in visits to a physician or medications. 8,9

Generally, the medical care costs consist of the direct costs and indirect costs. The direct costs are caused by the medical products or services such as visits to a physician, diagnostic workup, medication or hospitalization. The indirect costs are accompanied by reduced productivity of patient by disease and the absence as the expenses 'indirectly' associated with consumption of medical products or services. ${ }^{10,11}$ While some studies have been published on the medical care costs of GERD in comparisons between GERD and other digestive diseases, ${ }^{12-14}$ there has been only one study published on the comparison of medical care costs between ERD and NERD so far. ${ }^{15}$ Furthermore, there has been no paper on the medical care costs of GERD in Korea even though there have been a few with regard to the socioeconomic medical costs of obesity or depression. ${ }^{16,17}$ In the present study, we investigated the total direct medical care costs of ERD and NERD as well as their associated risk factors.

\section{Materials and Methods}

\section{Patients}

The patients were selected from the group which had been studied in our previous published paper regarding ERD and NERD in $2009 .^{18}$ The patients, who visited and underwent upper gastrointestinal endoscopic examinations by one gastroenterologist (N.K) under impression of GERD because of reflux symptoms, were enrolled. The data regarding the GERD symptoms and clinical characteristic symptoms were collected through the survey before EGD. In that survey, the 7 symptoms of GERD were heartburn, acid regurgitation, chest pain, globlus sensation, cough, epigastric dyspepsia and epigastric soreness and there were questions about frequency and severity. In addition, the questionnaire about the following factors was also given to each subjects: (1) the presence of diabetes mellitus or hypertension, (2) alcohol consumption and (3) smoking. The research assistants put the figures of the body mass index (BMI $)^{19}$ and biochemical test results, including triglyceride, high density lipoprotein, low density lipoprotein and Helicobacter pylori (H. pylori) tests such as Campylobacter like organism test (CLO test, Delta West, Bentley and Australia) or histology results. Since then, all study subjects with GERD symptoms underwent upper gastrointestinal endoscopic examinations, which were performed by one gastroenterologist (N.K) with 20 years of endoscopy experience and the endoscopic findings of ERD patients were classified using the Los Angeles classification (LA grades as A to D). ${ }^{20}$ Among the patients with no mucosal breaks on EGD, the patients who were positive for ambulatory 24-hour esophageal $\mathrm{pH}$ monitoring and/or acid perfusion test were defined as NERD. A positive test result for the ambulatory 24-hour esophageal $\mathrm{pH}$ monitoring was determined when an acid exposure were over $4.2 \%$ of the total time $(\mathrm{pH}<4)$ or a positive symptom index $(>50 \%) .{ }^{18} \mathrm{~A}$ positive test of the acid perfusion test was determined when the pain or discomfort similar to the symptoms of GERD occurred with the instillation of $0.1 \mathrm{~N} \mathrm{HCl}$ up to $70 \mathrm{~mL}$ and disappear after the acid solution replacement with $0.9 \%$ of normal saline solution. This procedure was repeated in order to confirm whether the test results were reliable. ${ }^{18}$ Exclusion criteria included a 
history of gastrointestinal surgery or systemic disease requiring chronic medication (except hypertension and diabetes mellitus). And if subjects were diagnosed as gastric ulcer, duodenal ulcer or gastroduodenal cancer by EGD, none of them were included in our study. The present study was performed in 178 ERD patients and 183 NERD patients from May 2003 through August 2006, which had been collected in the previous study. ${ }^{18}$ However, 27 from 205 ERD patients and 17 from 200 NERD patients who had been enrolled in the previous study ${ }^{18}$ were excluded in the present study mostly because the follow-up was not undergone up to 2 years. This study was approved by the Institutional Review Board of Seoul National University Bundang Hospital.

\section{Study protocol}

The medical costs of health resources were calculated including visits to a physician, diagnostic tests, medications, visits to emergency room and hospitalization for a period of 2 years since the first hospital visit for GERD symptoms. All of the enrolled patients had GERD symptoms and took proton pump inhibitors (PPIs). The diagnostic costs include expenses for the EGD, ambulatory 24-hour esophageal $\mathrm{pH}$ monitoring and esophageal manometry with acid perfusion test. The medication costs were restricted to the PPIs, $\mathrm{H}_{2}$-blockers, prokinetics and antacids (or sucralfate), the key drugs for GERD treatment. The costs caused by visits to emergency room and hospitalization were included when they were related to GERD. The unrelated or indirect medical care costs were excluded. The costs of drugs were defined by the price of notice of Ministry of Health \& Welfare. Other medical care costs were calculated based on medical insurance costs of Seoul National University Bundang Hospital.

\section{Statistical methods}

Categorical variables were analyzed with the $\chi^{2}$ test or Fisher's exact test, and continuous variables with Student's t test or Mann-Whitney U test. All continuous variables including costs were presented as mean $\pm \mathrm{SD}$, and the proportions were expressed as numbers. A p-value of $<0.05$ was considered statistically significant. All analyses were performed with SPSS statistical software package (SPSS 15.0 for Windows, SPSS Inc, Chicago, IL, USA).

\section{Results}

\section{Patients characteristics}

The ERD (LA-A 127 [71.3\%], LA-B 43 [24.2\%] and LA-C 8 [4.5\%]) was diagnosed on 178 of the 361 patients by EGD. The remaining 183 patients with GERD symptoms and

Table 1. Comparison of Clinical Characteristics Between Erosive Reflux Disease and Non-Erosive Reflux Disease

\begin{tabular}{|c|c|c|c|}
\hline Variable & $\operatorname{ERD}(\mathrm{n}=178)$ & $\operatorname{NERD}(\mathrm{n}=183)$ & $\mathrm{p}$-value \\
\hline Age (mean $\pm \mathrm{SD}, \mathrm{yr})$ & $54.8 \pm 14.0$ & $53.5 \pm 13.0$ & 0.176 \\
\hline Male (n $[\%])$ & $120(67.4)$ & $78(39.9)$ & 0.000 \\
\hline Alcohol use (n $[\%])$ & $93(50.9)$ & $53(29.8)$ & 0.000 \\
\hline Current smoker (n [\%]) & $55(31.0)$ & $29(16.0)$ & 0.001 \\
\hline Diabetes mellitus (n [\%]) & $10(5.5)$ & $12(6.3)$ & 0.755 \\
\hline Hypertension (n [\%]) & $50(28.0)$ & $33(17.8)$ & 0.027 \\
\hline H. pylori $(\mathrm{n}[\%])^{\mathrm{a}}$ & $23(46.9)$ & $22(51.2)$ & 0.686 \\
\hline Hiatal hernia (n [\%]) & $40(22.7)$ & $6.0(3.4)$ & 0.000 \\
\hline $\mathrm{BMI}\left(\right.$ mean $\left.\pm \mathrm{SD}, \mathrm{kg} / \mathrm{m}^{2}\right)$ & $24.5 \pm 3.0$ & $23.4 \pm 3.1$ & 0.386 \\
\hline$\geq 25(\mathrm{n}[\%])$ & $81(45.7)$ & $65(35.3)$ & 0.018 \\
\hline $23-24.9(\mathrm{n}[\%])$ & $56(31.4)$ & $49(26.9)$ & \\
\hline$<23(\mathrm{n}[\%])$ & $41(22.9)$ & $69(37.7)$ & \\
\hline Triglyceride $($ mean $\pm \mathrm{SD}, \mathrm{mg} / \mathrm{dL})$ & $161 \pm 88$ & $115 \pm 52$ & 0.001 \\
\hline$\geq 150(\mathrm{n}[\%])$ & $91(51.4)$ & $43(23.7)$ & \\
\hline $\mathrm{HDL}($ mean $\pm \mathrm{SD}, \mathrm{mg} / \mathrm{dL})$ & $52 \pm 12$ & $56 \pm 14$ & 0.230 \\
\hline$<40($ men $)<50($ women $)(\mathrm{n}[\%])$ & $46(26.1)$ & $41(22.4)$ & \\
\hline $\mathrm{LDL}($ mean $\pm \mathrm{SD}, \mathrm{mg} / \mathrm{dL})$ & $113.0 \pm 28.9$ & $112.0 \pm 30.5$ & 0.865 \\
\hline
\end{tabular}

${ }^{a}$ The test was performed in 49 in ERD and 43 in NERD, respectively.

ERD, erosive reflux disease; NERD, non-erosive reflux disease; H. pylori, Helicobacter pylori; BMI, body mass index; HDL, high density lipoprotein; LDL, low density lipoprotein.

Bold style indicates statistical significance. 
no ERD, showed positive response in the ambulatory 24-hour esophageal $\mathrm{pH}$ monitoring and/or the acid perfusion test. The clinical characteristics of patients with ERD and NERD are shown in Table 1 . There was statistically no significant differences between the 2 groups regarding age. More male patients $(67.4 \%)$ were found than females $(32.6 \%)$ in the ERD, whereas more females $(60.1 \%)$ were found than males $(39.9 \%)$ in the NERD ( $p=0.000)$. Risk factors of the ERD group include alcohol consumption, smoking, frequency of hiatal hernia, higher triglyceride $(\geq 150 \mathrm{mg} / \mathrm{dL})$ and higher BMI $\left(\geq 25 \mathrm{~kg} / \mathrm{m}^{2}\right)$. However, there was no significant difference in $H$. pylori infection rate, high density lipoprotein and low density lipoprotein levels. Covariates showing the significant association in the $\chi^{2}$ test were calculated using the multivariate logistic regression analysis. Altogether, ERD was more common in male (OR, 4.3; 95\% CI,

Table 2. Multivariate Logistic Regression Analysis for Characteristics of the Subjects

\begin{tabular}{llll}
\hline \multicolumn{1}{c}{ Variable } & $\mathrm{OR}^{\mathrm{a}}$ & $95 \% \mathrm{CI}$ & $\mathrm{p}$-value \\
\hline Male sex & 4.3 & $1.3-14.4$ & $\mathbf{0 . 0 1 8}$ \\
Alcohol use & 2.7 & $1.2-8.3$ & $\mathbf{0 . 0 4 2}$ \\
Current smoker & 0.9 & $0.3-3.9$ & 0.920 \\
$\mathrm{BMI} \geq 25$ & 3.1 & $1.1-9.7$ & $\mathbf{0 . 0 4 8}$ \\
Hiatal hernia & 5.0 & $1.1-22.3$ & $\mathbf{0 . 0 3 5}$ \\
$\quad \geq 1 \mathrm{~cm}$ & & & \\
Triglyceride & 4.5 & $1.7-11.6$ & $\mathbf{0 . 0 0 2}$ \\
$\geq 150 \mathrm{mg} / \mathrm{dL}$ & & & \\
\hline
\end{tabular}

${ }^{a}$ Odds ratio of erosive reflux disease over non-erosive reflux disease. $\mathrm{OR}$, odds ratio; $\mathrm{CI}$, confidence interval; $\mathrm{BMI}$, body mass index. Bold style indicates statistical significance.
1.3-14.4), with alcohol history (OR, 2.7; 95\% CI, 1.2-8.3), higher BMI ( $\geq 25 \mathrm{~kg} / \mathrm{m}^{2}$; OR, 3.1; 95\% CI, 1.1-9.7), patient with a hiatal hernia (OR, 5.0; 95\% CI, 1.1-22.3), and higher triglyceride levels ( $\geq 150 \mathrm{mg} / \mathrm{dL}$; OR, 4.5; 95\% CI, 1.7-11.6) (Table 2).

\section{Comparison of direct medical care costs between ERD and NERD group}

Comparison of direct medical care costs per person for 2 years of follow-up period between the ERD and NERD group are shown in Table 3 . The total direct medical care costs per person for 2 years were $\$ 384.8$ (ERD) and $\$ 412.9$ (NERD), respectively $(\mathrm{p}=0.364)$. With a closer look into the individual causal factors of the direct medical care costs, the costs related with visits to a physician were higher in the ERD group than in the NERD group but without significant difference. The medication costs were \$191.7 in ERD, \$182.0 in NERD, respectively and there was no statistical difference between the ERD and NERD group. The cost spent on PPI, the most important medicine in GERD treatment, was higher in ERD than in NERD which was statistically not different. Seventeen of 183 NERD patients $(9.3 \%)$ had emergency room visit history, which was higher than the $3.4 \%(6 / 178)$ of ERD patients ( $p=0.029)$. However, there was no statistical difference in the average medical costs per each patient related with emergency room visit $(p=0.817)$. A total of $7.1 \%$ of the NERD patients (13/183) had history of hospitalization, which was higher than $1.1 \%(2 / 178)$ of ERD patients $(\mathrm{p}=0.006)$ (Fig. 1A). In addition, the mean duration of hospitalization was 8.0 days in the 13 NERD patients compared

Table 3. Comparison of Medical Care Costs Between Erosive Reflux Disease and Non-erosive Reflux Disease During 2 Years

\begin{tabular}{lccc}
\hline \multicolumn{1}{c}{ Cost item } & ERD $(\mathrm{n}=178)$ & NERD $(\mathrm{n}=183)$ & p-value \\
\hline Visits to a physician (\$/person) ${ }^{\mathrm{a}}$ & $76.4 \pm 53.4$ & $67.53 \pm 43.6$ & 0.085 \\
Diagnostic tests (\$/person) & $110.3 \pm 78.6$ & $123.7 \pm 43.6$ & 0.088 \\
Medications (\$/person) & $191.7 \pm 152.4$ & $182.0 \pm 188.0$ & 0.637 \\
PPIs (\$/person) & $135.3 \pm 109.0$ & $125.9 \pm 124.9$ & 0.521 \\
H$_{2}$-blockers (\$/person) & $32.5 \pm 23.1$ & $35.6 \pm 48.0$ & 0.706 \\
Prokinetics (\$/person) & $22.4 \pm 26.4$ & $19.6 \pm 26.1$ & 0.313 \\
Antacids or sucralfate (\$/person) & $1.62 \pm 4.4$ & $0.9 \pm 2.8$ & 0.061 \\
No. of patients visiting emergency room & $\mathrm{n}=6$ & $\mathrm{n}=17$ & $\mathbf{0 . 0 2 9}$ \\
Emergency room costs (\$person) & $102.0 \pm 62.7$ & $81.0 \pm 18.1$ & 0.817 \\
No. of patients with hospitalization & $\mathrm{n}=2$ & $\mathrm{n}=13$ & $\mathbf{0 . 0 0 6}$ \\
Hospitalization costs (\$/person) & $213.9 \pm 31.3$ & $457.3 \pm 175.3$ & $\mathbf{0 . 0 3 8}$ \\
Total direct costs (\$/person) & $384.8 \pm 248.4$ & $412.9 \pm 287.1$ & 0.364
\end{tabular}

${ }^{\mathrm{a}}$ Exchange rate of Korean currency to US dollar is $1,250 \mathrm{Won} / \mathrm{US}$ dollar $(\$)$.

ERD, erosive reflux disease; NERD, non-erosive reflux disease; PPIs, proton pump inhibitors.

Bold style indicates statistical significance. 
to 2.5 days in ERD patients (Fig. 1B) and the average costs of hospitalization were higher in the NERD patients $(\mathrm{p}=0.038)$ (Table 3). However, the total direct medical costs were not significantly different between these 2 groups with slightly higher average fee in the NERD group. When we compared the expense factors of total direct medical care costs in the ERD and NERD, medications accounted for the major proportion and the second factor was the diagnostic expenses in both groups (Fig. 2).

\section{Discussion}

It is widely accepted that the risk factors related to ERD and NERD are different. The prevalence of ERD is higher in the group of male gender, old age, with smoking, overweight or alco- hol consumption but lower in the group with positive $H$. pylori in both the Western ${ }^{21-24}$ and Eastern countries. ${ }^{25,26}$ In contrast, NERD were more common in low BMI or female group. ${ }^{26}$ When we compared ERD and NERD, the prevalence of ERD was higher in the group of male gender, alcohol consumption, high BMI ( $\geq 25 \mathrm{~kg} / \mathrm{m}^{2}$ ), hiatal hernia or high triglyceride levels ( $\geq 150 \mathrm{mg} / \mathrm{dL}$ ). In addition, it has been reported that the proportion of patients with NERD responding to standard dose of PPI was around $20 \%$ to $30 \%$, a lower response compared to the ERD group. ${ }^{8,9}$ In the aspect of symptoms, the extraesophageal symptoms were more common in the NERD patients than the ERD patients ${ }^{26,27}$ and double dose of PPI was often necessary for the symptom relief of the extraesophageal symptoms compared to the esophageal symptoms. ${ }^{28-31}$

Based on this background, we hypothesized that total medi-
A

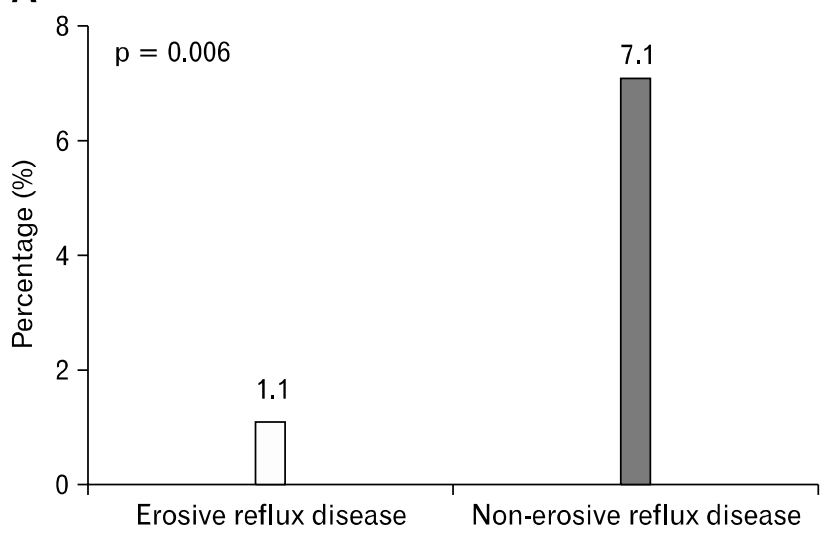

B

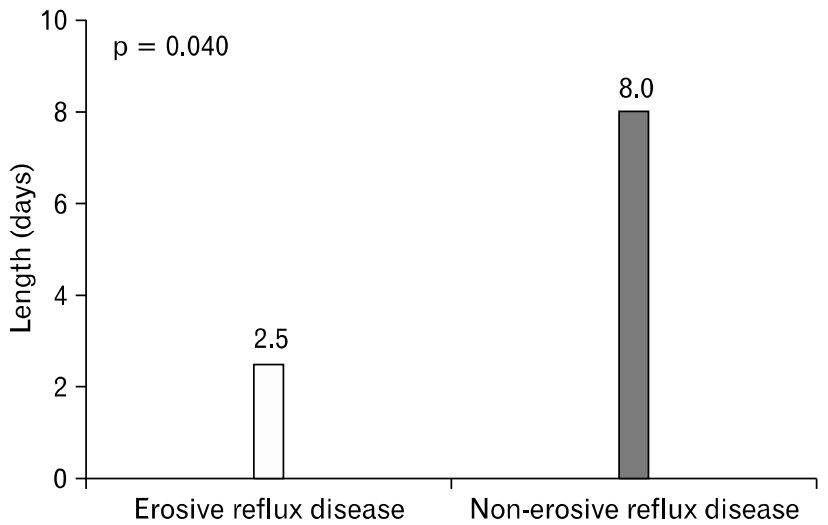

Figure 1. Hospitalization history (A) and hospitalization length (B) in the erosive reflux disease (ERD) and non-erosive reflux disease (NERD). The hospitalization history was found in the 2 of 178 ERD patients (1.1\%) and 13 of 183 NERD patients (7.1\%) (A). Mean hospitalization length was calculated in the 2 of ERD and 13 of NERD patients, respectively (B).

A

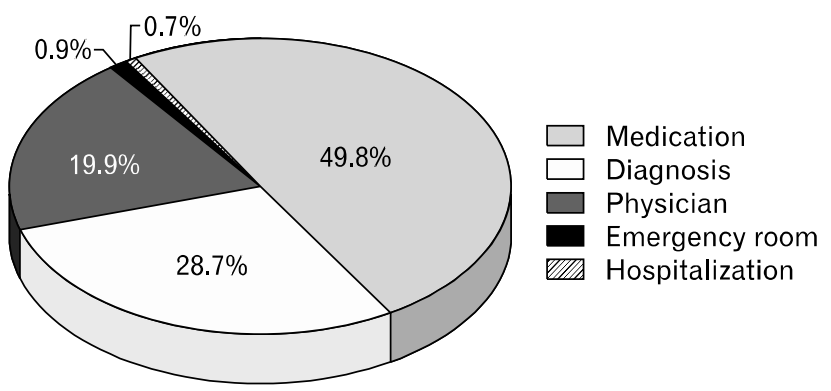

B Non-erosive reflux disease

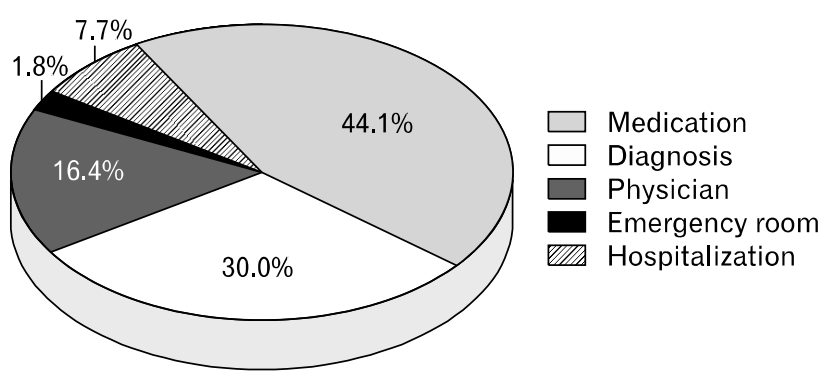

Figure 2. Distribution of total direct medical cost factors in erosive reflux disease (A) and non-erosive reflux disease group (B). Each factor contribution to total direct medical costs was calculated by percentage. 
cal care costs caused by ERD or NERD could be different. On the contrary, the total direct medical care costs for 2 years were not significantly different between the ERD (\$384.8) and NERD (\$412.9) and the visiting numbers to physician were similar in both groups, as 7.3 (ERD) and 6.3 (NERD), respectively. The total direct medical care costs of the first year were $\$ 331.3$ (ERD) and $\$ 352.2$ (NERD), and the numbers of the outpatient visit were 6.1 (ERD) and 5.5 (NERD), respectively. The total direct medical care costs of the second year were only $\$ 53.5$ (ERD) and $\$ 60.7$ (NERD), and the average number of visit to a physician was around 1 time in both groups. The medical costs of the second year were small (13.9\% for ERD, $14.7 \%$ for NERD group based on the total direct medical care costs) compared to the first year, suggesting that once the GERD symptoms have improved, then the patients preferred local clinics for on demand therapy instead of visiting specialists. As it was unfeasible to calculate the expenses caused by medical source services with current Korean medical system, the medical costs might have been underestimated in the present study.

After 4-week of standard PPI treatment, more than $50 \%$ of symptom was decreased in the $86.3 \%$ of ERD and $76.2 \%$ of the NERD patients. The refractory response was observed in $7.3 \%$ of ERD and $15.5 \%$ of NERD patients respectively, in the previous study. ${ }^{18}$ Consistently, more NERD patients (36.5\%) had extraesophageal symptoms (cough and globus sensation) compared to ERD patients $(10.1 \%) .{ }^{18}$ Even though NERD patients had more refractory responses and extraesophageal symptoms, there was no statistical difference in the medical costs caused by hospital visit and PPI medication. This indicates that during the investigated period, ERD patients had continuous or intermittent medication prescriptions more often than NERD patients because ERD patients had more typical symptoms which were responsive to the medications than NERD patients.

Although the hospitalizations in the $\operatorname{ERD~(2~patients,~1.1\% )~}$ and NERD (13 patients, 7.1\%) group were relatively few in number, the hospitalization fee per admitted person was significantly higher in the NERD group and the hospitalization durations in NERD patients were 3 times longer (average 8 days) than the 2 ERD patients (average 2.5 days), with statistically significant difference $(\mathrm{p}=0.040)$. There was not much difference in the medical costs, however visits to emergency room were more frequent in NERD (17/183, 9.3\%) than $\operatorname{ERD}(6 / 178,3.4 \%)$ patients $(\mathrm{p}=0.029)$. The NERD patients with more histories of visits to emergency room and hospitalization might be related to the fact that NERD patients are less responsive to PPI medi- cation and present with more frequent refractory responses than ERD patients.

The present study showed that the first major causal factor of the total direct medical care costs was the medication fee in both subtypes of GERD. The expense proportion of medications was $49.8 \%$ (ERD) and $44.1 \%$ (NERD) respectively. These results are consistent with other reports on the medical care costs for GERD in USA or European countries. ${ }^{32-34}$ On demand therapy is known to be effective for the long term treatment of NERD ${ }^{35}$ whereas continuous maintenance therapy has been reported to be more effective in patients with ERD. ${ }^{36,37}$ However, our previous study with similar study population has shown that the proportion of on demand therapy was similar in the ERD (47.6\%) and NERD patients (41.6\%). The relapse rates were found to be $44.3 \%$ for patients with ERD and $43.2 \%$ for patients with NERD during a follow up period of 1 year. ${ }^{18}$ Taken together, the high relapse rates and on demand therapy rates of ERD and NERD might have contributed to the high cost of medications in both groups of the present study.

The present study, which analyzed the direct medical care costs between NERD and ERD in Korea for the first time, has several limitations. First, our analysis has been based on the medical care costs happened in the Seoul National University Bundang Hospital alone which is because the medical care cost data in other hospitals or primary care units are not available under current Korean medical system. However, most of the GERD patients in our study reported that they had visited local clinics for on demand therapy. Therefore, we have reasoned that the major costs might have occurred in the Seoul National University Bundang Hospital. Secondly, since the direct medical care costs are mainly regulated by government in Korea, they are rather cheap compared to Western countries. The general GERD medical care costs in our study were lower than that in most studies based on European or American population. ${ }^{11,15,38,39}$ Third, it is possible that the patients with more severe symptom or refractory response to PPI might be included in NERD patients group because NERD patients were defined by the positive results on the ambulatory 24-hour esophageal $\mathrm{pH}$ monitoring and/or acid perfusion test. PPI test has become popular as one of the recent diagnostic methods for NERD but this modality is still under study and has to be defined better for a reliability. Therefore, we restricted the diagnosis of NERD to those who showed positivity on the ambulatory 24-hour esophageal $\mathrm{pH}$ monitoring and/or the acid perfusion test. In the future, further study is necessary to overcome this limitation of the present study 
in terms of selection bias.

In spite of these 3 limitations the present study is meaningful since it compared the total direct medical care costs between ERD and NERD for the first time in Korea as well as in Asia.

In conclusion, the total direct medical care costs were similar in the ERD and NERD group in spite of the different risk factors for ERD and NERD. However, NERD patients visit to emergency room more often and have more hospitalization costs indicating that the medical service and usage distribution are different between the 2 groups.

\section{References}

1. Vakil N, van Zanten SV, Kahrilas P, Dent J, Jones R. The Montreal definition and classification of gastroesophageal reflux disease: a global evidence-based consensus. Am J Gastroenterol 2006;101: 1900-1920.

2. Dent J, El-Serag HB, Wallander MA, Johansson S. Epidemiology of gastro-oesophageal reflux disease: a systematic review. Gut 2005;54:710-717.

3. Pace F, Bianchi Porro G. Gastroesophageal reflux disease: a typical spectrum disease (a new conceptual framework is not needed). Am J Gastroenterol 2004;99:946-949.

4. Pace F, Bollani S, Molteni P, Bianchi Porro G. Natural history of gastro-oesophageal reflux disease without oesophagitis (NERD) - a reappraisal 10 years on. Dig Liver Dis 2004;36:111-115.

5. Barlow WJ, Orlando RC. The pathogenesis of heartburn in nonerosive reflux disease: a unifying hypothesis. Gastroenterology 2005; 128:771-778.

6. Fass R. Distinct phenotypic presentations of gastroesophageal reflux disease: a new view of the natural history. Dig Dis 2004;22:100-107.

7. Fass R, Tougas G. Functional heartburn: the stimulus, the pain, and the brain. Gut 2002;51:885-892.

8. Dean BB, Gano AD Jr, Knight K, Ofman JJ, Fass R. Effectiveness of proton pump inhibitors in nonerosive reflux disease. Clin Gastroenterol Hepatol 2004;2:656-664.

9. Fass R. Erosive esophagitis and nonerosive reflux disease (NERD): comparison of epidemiologic, physiologic, and therapeutic characteristics. J Clin Gastroenterol 2007;41:131-137.

10. Joish VN, Donaldson G, Stockdale W, et al. The economic impact of GERD and PUD: examination of direct and indirect costs using a large integrated employer claims database. Curr Med Res Opin 2005;21:535-544.

11. Levin TR, Schmittdiel JA, Kunz K, et al. Costs of acid-related disorders to a health maintenance organization. Am J Med 1997; 103:520-528.

12. Holzer SS, Juday TR, Joelsson B, Crawley JA. Determining the cost of gastroesophageal reflux disease: a decision analytic model. Am J Manag Care 1998;4:1450-1460.

13. Sandler RS, Everhart JE, Donowitz M, et al. The burden of selected digestive diseases in the United States. Gastroenterology 2002;122: 1500-1511.

14. Rezailashkajani M, Roshandel D, Shafaee S, Zali MR. A cost analy- sis of gastro-esophageal reflux disease and dyspepsia in Iran. Dig Liver Dis 2008;40:412-417.

15. Willich SN, Nocon M, Kulig M, et al. Cost-of-disease analysis in patients with gastro-oesophageal reflux disease and Barrett's mucosa. Aliment Pharmacol Ther 2006;23:371-376.

16. Ahn BC, Joung H. Socioeconomic cost of obesity in Korea. Korean J Nutr 2005;38:786-792.

17. Kim W, Hwang TY, Ham BJ, et al. The impact of major depressive disorder on productivity in workers: a preliminary study using WHO-HPQ (Health and Work Performance Questionnaire). J Korean Neuropsychiatr Assoc 2007;46:587-595.

18. Lee ES, Kim N, Lee SH, et al. Comparison of risk factors and clinical responses to proton pump inhibitors in patients with erosive oesophagitis and non-erosive reflux disease. Aliment Pharmacol Ther 2009;30:154-164.

19. Shiwaku K, Anuurad E, Enkhmaa B, Kitajima K, Yamane Y. Appropriate BMI for Asian populations. Lancet 2004;363:1077.

20. Armstrong D, Bennett JR, Blum AL, et al. The endoscopic assessment of esophagitis: a progress report on observer agreement. Gastroenterology 1996;111:85-92.

21. Labenz J, Jaspersen D, Kulig M, et al. Risk factors for erosive esophagitis: a multivariate analysis based on the ProGERD study initiative. Am J Gastroenterol 2004;99:1652-1656.

22. Collen MJ, Abdulian JD, Chen YK. Gastroesophageal reflux disease in the elderly: more severe disease that requires aggressive therapy. Am J Gastroenterol 1995;90:1053-1057.

23. Endlicher E, Gelbmann CM, Messmann H. Reflux disease and Barrett's oesophagus - are there gender-specific differences? Z Gastroenterol 2009;47:1065-1068.

24. Aro P, Ronkainen J, Talley NJ, Storskrubb T, Bolling-Sternevald E, Agreus L. Body mass index and chronic unexplained gastrointestinal symptoms: an adult endoscopic population based study. Gut 2005;54:1377-1383.

25. Fujiwara $\mathrm{Y}$, Higuchi K, Shiba M, et al. Differences in clinical characteristics between patients with endoscopy-negative reflux disease and erosive esophagitis in Japan. Am J Gastroenterol 2005;100: 754-758.

26. Kim N, Lee SW, Cho SI, et al. The prevalence and risk factors of erosive oesophagitis and non-erosive reflux disease: a nationwide multicentre prospective study in Korea. Aliment Pharmacol Ther 2008;27:173-185.

27. Lee SH, Choi MG, Park SH, et al. The clinical spectrum of gastroesophagel reflux disease in Korea. Korean J Gastrointest Motil 2000;6:1-10.

28. Kiljander TO, Harding SM, Field SK, et al. Effects of esomeprazole $40 \mathrm{mg}$ twice daily on asthma: a randomized placebo-controlled trial. Am J Respir Crit Care Med 2006;173:1091-1097.

29. Park W, Hicks DM, Khandwala F, et al. Laryngopharyngeal reflux: prospective cohort study evaluating optimal dose of proton-pump inhibitor therapy and pretherapy predictors of response. Laryngoscope 2005;115:1230-1238.

30. Spechler SJ, Lee E, Ahnen D, et al. Long-term outcome of medical and surgical therapies for gastroesophageal reflux disease: follow-up of a randomized controlled trial. JAMA 2001;285:2331-2338.

31. Harding SM, Richter JE, Guzzo MR, Schan CA, Alexander RW, Bradley LA. Asthma and gastroesophageal reflux: acid suppressive 
therapy improves asthma outcome. Am J Med 1996;100:395-405.

32. Vakil N. Review article: cost-effectiveness of different GERD management strategies. Aliment Pharmacol Ther 2002;16(suppl 4): 79-82.

33. Agréus L, Borgquist L. The cost of gastro-oesophageal reflux disease, dyspepsia and peptic ulcer disease in Sweden. Pharmacoeconomics 2002;20:347-355.

34. Schwenkglenks M, Marbet UA, Szucs TD. Epidemiology and costs of gastroesophageal reflux disease in Switzerland: a population-based study. Soz Praventivmed 2004;49:51-61.

35. Lind T, Havelund T, Lundell L, et al. On demand therapy with omeprazole for the long-term management of patients with heartburn without oesophagitis - a placebo-controlled randomized trial. Aliment Pharmacol Ther 1999;13:907-914.
36. Sjöstedt S, Befrits R, Sylvan A, et al. Daily treatment with esomeprazole is superior to that taken on-demand for maintenance of healed erosive oesophagitis. Aliment Pharmacol Ther 2005;22:183-191.

37. Johnsson F, Moum B, Vilien M, Grove O, Simren M, Thoring M. On-demand treatment in patients with oesophagitis and reflux symptoms: comparison of lansoprazole and omeprazole. Scand J Gastroenterol 2002;37:642-647.

38. Brook RA, Wahlqvist $\mathrm{P}$, Kleinman NL, Wallander MA, Campbell SM, Smeeding JE. Cost of gastro-oesophageal reflux disease to the employer: a perspective from the United States. Aliment Pharmacol Ther 2007;26:889-898.

39. Bloom BS, Jayadevappa R, Wahl P, Cacciamanni J. Time trends in cost of caring for people with gastroesophageal reflux disease. Am J Gastroenterol 2001;96:S64-S69. 